\title{
Dialogue Analysis Using a Text Mining Approach: Case Study of Hirono Town
}

\author{
Madoka Chosokabe (Corresponding author) \\ Department of Social Systems and Civil Engineering, Tottori University \\ 4-101, Koyama-Minami, Tottori 680-8552, Japan \\ Tel: 81-857-31-5311Ｅ-mail: mchoso@sse.tottori-u.ac.jp
}

Maiko Sakamoto \& Mikiyasu Nakayama

Graduate School of Frontier Sciences, The University of Tokyo

5-1-5 Kashiwano-ha, Kashiwa, Chiba 277-8563, Japan

Received: January 10, 2017 Accepted: February 5, 2017 Published: February 28, 2017

doi:10.5296/jad.v3i1.10583 URL: http://dx.doi.org/10.5296/jad.v3i1.10583

\begin{abstract}
This case study examined public participation regarding reconstruction of the disaster-affected areas in the Fukushima Prefecture of Japan following the Great East Japan Earthquake in March 2011. The study aimed at (i) identifying the topics discussed and shared by the residents, and (ii) revealing the contribution of the media to ensuring information transparency in the regional planning process. We applied text mining-in particular, correspondence analysis - to (a) the text data from dialogue sessions with local residents and (b) newspaper articles that appeared in a nation-wide newspaper in order to identify the similarities and differences between the topics discussed by session participants and those that appeared in newspaper articles. It turned out that the newspaper articles did not adequately address some important topics discussed in the dialogues. This implies that the coverage by the mass media has much room for improvement in the transparency of the information it provides and supporting the development and implementation of administrative agendas involving citizens and municipalities.
\end{abstract}

Keywords: text mining, correspondence analysis, information transparency, Fukushima 


\section{Introduction}

After the Great East Japan Earthquake of 2011, the municipal governments of the impacted areas started promoting the reconstruction of the disaster-affected areas. Promoting the reconstruction through communication among the citizens and through a subsequent learning process was regarded as very important so that each individual resident could participate proactively in the planning process, which would lead to the revitalization of regional communities (MEXT, 2011).

In the participatory planning process for consensus building and decision-making, local government officers organized small group discussions (workshops) with residents, not only to understand their views but also to create appropriate alternatives by listening to them. Two of the most important aspects of this process are how to aggregate participants' opinions and how to adopt them to make relevant plans. However, in this case, the contents of the discussions were not necessarily used and applied effectively to policy formulation. In addition, the concerns and information discussed by the participants in the workshops were not adequately shared with other residents who had not participated. Thus, a system should be established to appropriately reflect the opinions of the residents and integrate them into the planning to ensure "process transparency." Process transparency implies that decision making process itself and the opinion and behavior of any participating organization or individual are visible for all the stakeholders. Additionally, it is discussed that not only "process transparency" but also "information transparency" is important for decision-making process. It required keeping information transparency between political decision maker and local residents.

This study intended to identify the topics discussed and shared by the residents in the workshops and, using text mining methodology, to reveal the contribution of the media to ensuring information transparency in the regional planning process for recovery from the disaster.

The remainder of the paper is organized as follows. Section 2 describes information transparency and the role of the media. Section 3 discusses the methodology of the study. Section 4 analyzes the results, and section 5 concludes the paper.

\section{Information Transparency and the Role of the Media}

The disaster-affected regions in Japan's Fukushima Prefecture are now experiencing challenges that did not exist before. Such challenges include, inter alia, fragmentation and disbanding of communities, particularly in the generation raising children, which are caused by the long-standing evacuation and "health-related anxieties"; the need for revitalizing agriculture; reputational damage; and an overwhelming number of workers who reside temporarily to the population (Hirono town, 2016). Because regional collaboration across a wide area is required for future town planning, it is desirable to share regional reconstruction stages and tasks widely. In addition, a system with a mechanism to appropriately identify the opinions of the residents and integrate these into the planning should be established to ensure "process transparency" during the reconstruction of the disaster-affected areas (Hirono town, 
2016).

"Information transparency" among political decision makers, local government officers and residents is also important for the reconstruction process from the disaster. Sharing correct information enhances smooth communication and decision-making. The media is expected to play an important role in attaining such information transparency at the residents' level. In the field of political science, it has been discussed that newspaper articles may reflect a community's recognition of issues (Brains \& Wattenberg, 1969; Prince, 1989). However, the following study has identified some of the problems with media reporting. Mannarinia and Roccato (2011) analyzed the uses of the term NIMBY ("not in my back yard") in the major Italian newspapers, and showed that there were multiple and diverse descriptions about NIMBY conflicts based on different ideas and principles.

This study was designed to identify the topics discussed and shared by the residents, and reveal the contribution of the media in ensuring information transparency in the regional planning process. A text mining approach was employed as the research methodology.

\section{Methodology}

\subsection{Data}

The source of residents' opinions was dialogue data from the international forum, "Thinking from disaster affected areas and Hirono." This forum was held in the town of Hirono from September 14-20, 2015, where the affected residents and the international participants discussed the issues together (Hirono town, 2016). During the forum, 15 international experts from the United States, Europe, Asia, and Africa gave keynote speeches and attended the keynote sessions, which involved active and diverse discussions from global perspectives.

The source of media representations of these same issues and opinions was newspaper articles. We collected articles from the past five years (March 11, 2011 to December 31, 2015) from the Asahi Shimbun, a national Japanese language newspaper.

\subsection{Text Mining Approach}

Text mining has been applied to dialogue data to reveal the topics of discussion and the changes of topics through time. For example, Jeong et al. (2007, 2008) proposed a methodology to investigate objectively the level of discourse similarity and interest dissonance among participants in public debates, by using discourse analysis based on corpus semantics. Chosokabe et al. (2012) proposed a methodology based on text mining for conducting quantitative analysis of workshop discussions. They also evaluated the priority to adapt opinions from the social context perspective, such as using newspaper articles (Chosokabe et al., 2016).

This study conducted three types of analyses-session-based, newspaper-based, and session-and-newspaper based. Whereas the session-based analysis shows the kinds of keywords the participants used in the sessions to express their concerns and to describe their situations, the newspaper-based analysis shows the kinds of keywords journalists used in newspaper articles to report the reconstruction situation. The session-and-newspaper based 
analysis reveals the differences between the topics discussed by the participants and those reported by the journalists.

\subsection{Correspondence Analysis}

We applied correspondence analysis to the text data of dialogue sessions and newspaper articles to clarify the similarities and differences between the topics discussed by participants and those that appeared in newspaper articles. Correspondence analysis is a multivariate analysis technique for exploring cross-tabular data by converting such tables into graphical displays called "maps," and related numerical statistics (Greenacre \& Blasius, 1994). This analysis reveals the structure of a complex data matrix without losing essential information (Clausen, 1998). In other words, it maps the associations between rows and columns in a frequency table, graphically, as points in a space of few dimensions (Clausen, 1998).

The following steps were taken for correspondence analysis in this study:

(i) To apply morphological analysis to the text data and extract only nouns from it.

(ii) To count the nouns in each discussion session or each newspaper article and make a cross-tabulation table. Low-frequency nouns, i.e., those used less than four times in total, are not analyzed.

(iii) To extract the top 100 nouns for correspondence analysis based on relative frequency in total.

(iv) To apply correspondence analysis to the frequency table. The row header represents each noun and the column header represents each discussion or each newspaper article. It shows how many times nouns are used in each discussion session or each newspaper article.

We used KH Coder in steps (i) and (ii). KH Coder is the software for content analysis and text mining (Higuchi, 2001).

Applying correspondence analysis to a cross-tabulation table consisting of multiple categories - in our case, nouns and sessions or nouns and newspaper articles-provides a two-dimensional solution for each category. In step (iv), the score in two dimensions was calculated and mapped first for 100 words and sessions and then separately for 100 words and newspaper articles. This revealed the relationships between nouns used frequently by participants in the sessions to express their concerns and situations, and those nouns that appeared in newspaper articles reporting on the situations of the residents in the disaster-affected areas.

\section{Results}

\subsection{Data Collection}

\subsubsection{Discussion Data}

A total of 15 dialogue sessions were held at the international forum at Hirono, six of which were used for this analysis. Transcripts of the six sessions were made from recordings of the discussion. In session $\mathrm{A}, 17$ junior town officers, one from each municipality in Futaba 
district, discussed the further strengthening of cooperation among their towns. In sessions B, $\mathrm{C}$, and D, the participants had small group discussions under the topics of "education," "medicine, health, and social welfare," and "industry," respectively. In sessions E and F, the panelists and the audience exchanged opinions on the topics of "the safety of Hirono" and "the role of journalists at the disaster," respectively. Table 1 shows the description of the sessions from which the dialogue data was drawn. We analyzed all utterances of participants in each session, except for the facilitators.

Table 1. Details of six sessions at the Hirono International Forum in 2015

\begin{tabular}{llllllll}
\hline ID & A & B & C & D & E & F \\
\hline Themes & $\begin{array}{l}\text { Junior town } \\
\text { officer }\end{array}$ & Education & $\begin{array}{l}\text { Health and } \\
\text { welfare }\end{array}$ & Industry & $\begin{array}{l}\text { Safety } \\
\text { security }\end{array}$ & $\begin{array}{l}\text { Role } \\
\text { journalists }\end{array}$ \\
\hline Date & Sept. 15 & Sept. 16 & Sept. 16 & Sept. 16 & Sept. 17 & Sept. 18 \\
Time (min.) & 85 & 71 & 69 & 72 & 139 & 159 \\
Speakers & 17 & 7 & 6 & 8 & 7 & 7 \\
Nouns & 2843 & 962 & 891 & 790 & 2448 & 2279
\end{tabular}

Note. "Themes" refers to the theme for discussion in each session. "Date" is the date of the discussion session. "Time" is the total discussion time in each session. "Speakers" refers to the number of different speakers; this includes participants who spoke and excludes facilitators. "Nouns" is the total number of nouns used in each session.

\subsubsection{Newspaper Articles}

To collect the text data from newspaper articles, we used Kikuzo II Visual, one of Japan's largest online databases of newspaper articles. Asahi Shimbun, a national Japanese newspaper, provides this database. All articles that appeared in Asahi Shimbun between March 11, 2011 and December 31, 2015 were eligible; those that included the keywords "Hirono" and "reconstruction" were extracted for analysis. Table 2 shows the description of the newspaper data.

Table 2. Details of newspaper articles that reported about Hirono town (Mar. 11, 2011-Dec. 31, 2015)

\begin{tabular}{llllll}
\hline ID & I & II & III & IV & V \\
\hline Year & 2011 & 2012 & 2013 & 2014 & 2015 \\
Articles & 57 & 74 & 70 & 45 & 80 \\
Characters & 143130 & 125976 & 67217 & 60348 & 93241 \\
Nouns & 16699 & 15150 & 9977 & 7897 & 11031 \\
\hline
\end{tabular}

Note. "Year" is the publication year of newspaper articles. "Articles" is the number of newspaper articles in each publication year. "Characters" is the total number of characters of newspaper articles in each publication year. "Nouns" is the total number of nouns used in the newspaper articles in each publication year. 


\subsection{Session-Based Analysis}

Following the above-mentioned steps, we first analyzed the data from the sessions. The 100 nouns used most frequently in the sessions were determined. These nouns are shown in Table 3. Correspondence analysis was applied to these nouns for each session. The result of this session-based analysis is shown in Figure 1. The plotted numbers from 1 through 100 represent the nouns, and letters $\mathrm{A}$ through $\mathrm{F}$ represent the sessions. The contribution rates were $28.75 \%$ for dimension 1 and $22.25 \%$ for dimension 2 . It means that the first dimension explains $28.75 \%$ of the data, whereas the second dimension explains $22.25 \%$ of it.

Table 3. Top 100 nouns in Japanese for session-based analysis

\begin{tabular}{|c|c|c|c|c|c|c|c|}
\hline ID & Nouns & ID & Nouns & ID & Nouns & ID & Nouns \\
\hline 1 & Hirono & 26 & repatriation & 51 & high school & 76 & meaning \\
\hline 2 & earthquake disaster & 27 & part & 52 & family & 77 & opinion \\
\hline 3 & evacuation & 28 & activity & 53 & education & 78 & work \\
\hline 4 & Futaba & 29 & Namie & 54 & state & 79 & transfer of schools \\
\hline 5 & Fukushima & 30 & Tomioka & 55 & support & 80 & favor \\
\hline 6 & school & 31 & teacher & 56 & whole country & 81 & Soma \\
\hline 7 & situation & 32 & lifting & 57 & town hall & 82 & locale \\
\hline 8 & saying & 33 & information & 58 & reporter & 83 & responding \\
\hline 9 & child & 34 & one & 59 & compensation & 84 & town \\
\hline 10 & life & 35 & staff & 60 & facility & 85 & nuclear power \\
\hline 11 & myself & 36 & industry & 61 & project & 86 & housing \\
\hline 12 & resident & 37 & together & 62 & question & 87 & Tsunami \\
\hline 13 & Iwaki & 38 & relationship & 63 & retail selling & 88 & innovation \\
\hline 14 & reconstruction & 39 & everyone & 64 & advanced age & 89 & plan \\
\hline 15 & locality & 40 & Tokyo & 65 & supermarket & 90 & damage \\
\hline 16 & job & 41 & local governments & 66 & public administration & 91 & radioactivity \\
\hline 17 & local area & 42 & healthcare & 67 & impression & 92 & basic \\
\hline 18 & cooperation & 43 & interview & 68 & reporting & 93 & vision \\
\hline 19 & workers & 44 & decontamination & 69 & discussion & 94 & article \\
\hline 20 & Naraha & 45 & region & 70 & individual & 95 & birthplace \\
\hline 21 & everybody & 46 & environment & 71 & community & 96 & Kawauchi \\
\hline 22 & previous & 47 & town people & 72 & student & 97 & handling \\
\hline 23 & $\begin{array}{l}\text { nuclear power } \\
\text { plant }\end{array}$ & 48 & municipality & 73 & talking & 98 & agenda \\
\hline 24 & Okuma & 49 & place & 74 & nursing care & 99 & thoughts \\
\hline 25 & accident & 50 & actual state & 75 & operation & 100 & Oneself \\
\hline
\end{tabular}

Note. These words are the top 100 nouns in Japanese based on relative frequency in total. Each word has a frequency for each session. We applied correspondence analysis to the cross-tabulation table of these words. Italicized words show the names of towns.

In Figure 1, session B was plotted far from the other sessions, indicating that the nouns used 


\section{Macrothink}

by the participants in session B were different from those used in the other sessions. In addition, the nouns used in session $\mathrm{F}$ were unique as compared to those used in the other sessions.

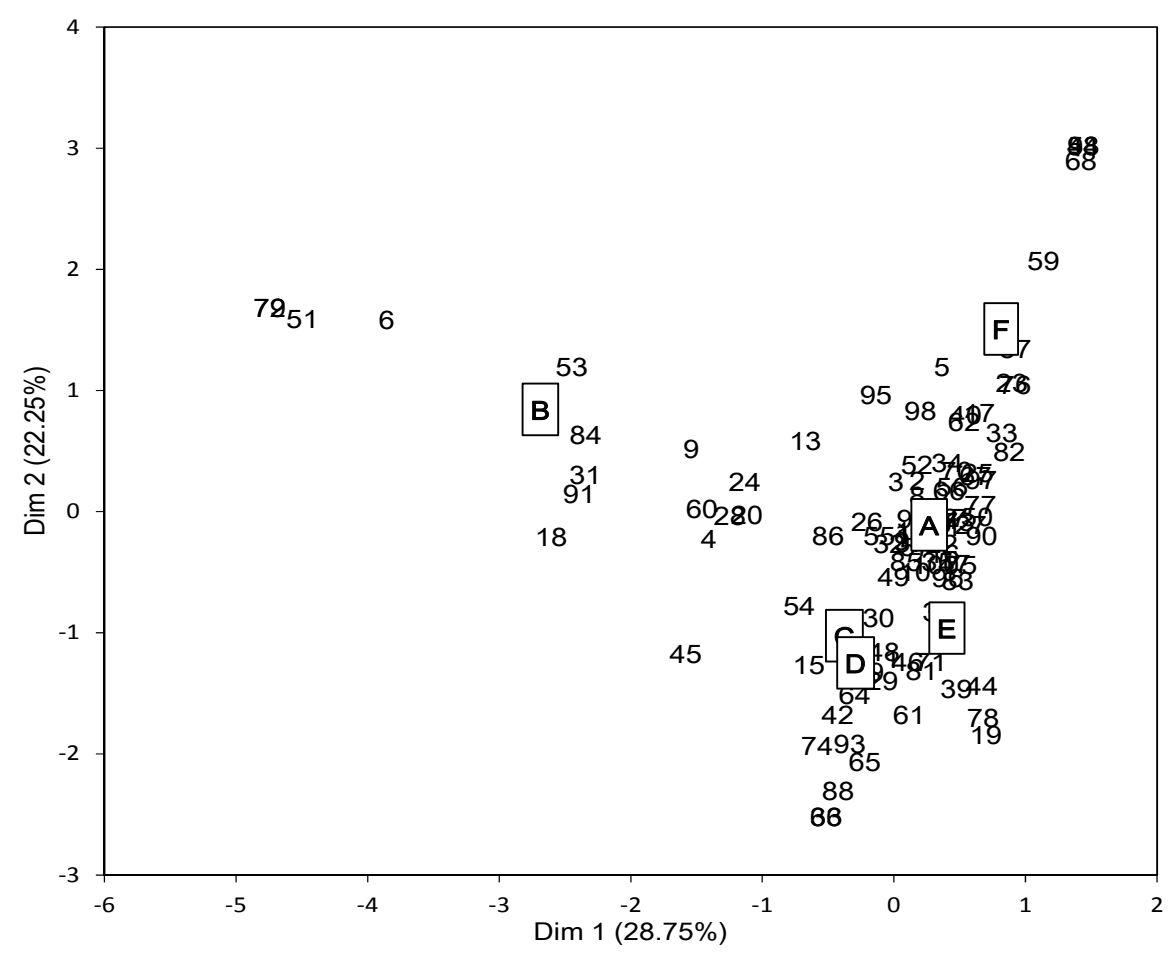

Figure 1. Result of the correspondence analysis of each session

Note. The numbers from 1 through 100 represent the nouns, and letters A through F represent the sessions.

The plotting of nouns close to the sessions and far from the origin reveals that these nouns were specifically mentioned by the participants in each session. Examples of the nouns used in each session are as follows (see also Figure 1 and Table 3):

- Session B (Education): "student" (No. 72), "transfer of schools" (No. 79), "high school" (No. 51), "school” (No. 6), "education" (No. 53), "town" (No. 84), "teacher" (No. 31), "radioactivity" (No. 91), and "cooperation" (No. 18). These nouns suggest the key issue for the residents under the topic of education related to "transfer of schools after the nuclear accident," reflecting that many students had to transfer from their school to another.

- Session D (Industry): “industry" (No. 36), "retail selling” (No. 63), "innovation" (No. 88), "vision" (No. 93), and "supermarket" (No. 65). These nouns suggest the key issue for residents under the topic of industry was related to "local retail shops in the disaster-affected area."

- Session E (Safety and security): "workers" (No. 19), "work" (No. 78), "everyone" (No. 39), and "decontamination" (No. 44). These nouns suggest the key issues for residents under the topic of safety and security related to "workers at nuclear power plants and workers for decontamination."

- Session F (Journalist): “reporting” (No. 68), “interview” (No. 43), "reporter” (No. 58), 


\section{Macrothink}

“article" (No. 94), and "compensation" (No. 59). These nouns suggest the topic related to "interview and reporting about compensation."

\subsection{Newspaper-Based Analysis}

Table 4 shows the 100 nouns used most frequently in newspaper articles as identified in the newspaper-based analysis. We counted nouns for each session in the previous analysis, whereas we counted the nouns of newspaper articles by publication year in this analysis. We applied correspondence analysis to the cross-tabulation table of these nouns. The result of the newspaper-based analysis is shown in Figure 2. The contribution rates were $46.91 \%$ for dimension 1 and $30.36 \%$ for dimension 2. Roman numerals I to $\mathrm{V}$ represent the publication year of the newspaper article.

In Figure 2, articles from years 2011 (I) through 2015 (V) were plotted by dividing the x-axis into right and left sides; I and II (during 2011-2012), and III, IV, and V (during 2013-2015). The examples of the nouns used in newspaper articles each year are as follows (see also Figure 2):

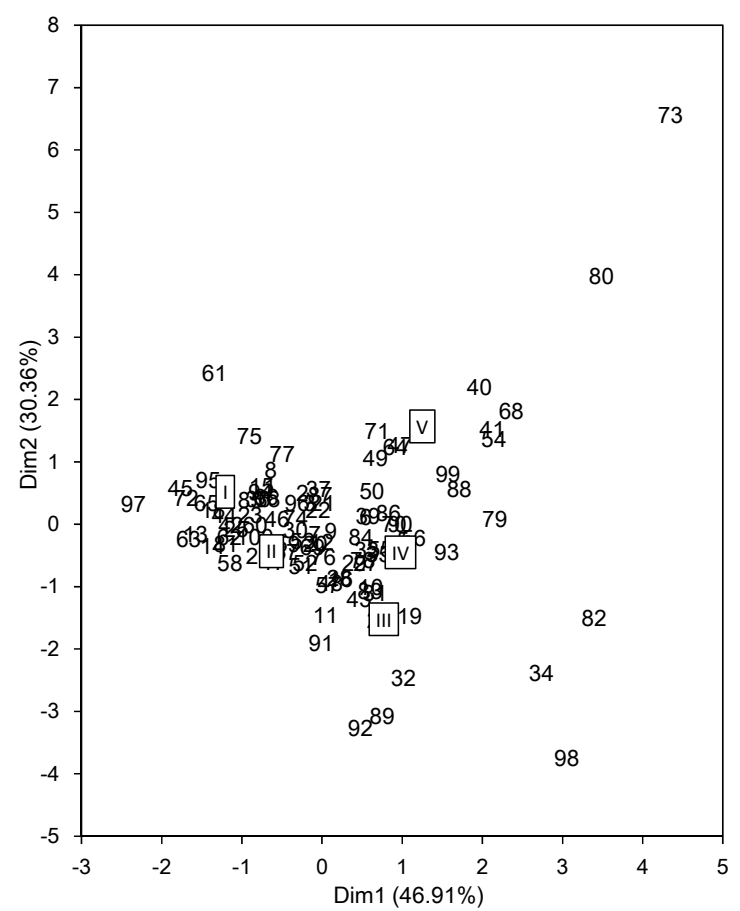

Figure 2. Result of correspondence analysis of each newspaper article

Note. The numbers from 1 through 100 represent the nouns, and Roman numerals I through V represent the publication year of newspaper articles. 


\section{Macrothink}

Table 4. Top 100 nouns of newspaper-based analysis

\begin{tabular}{|c|c|c|c|c|c|c|c|}
\hline ID & Nouns & ID & Nouns & ID & Nouns & ID & Nouns \\
\hline 1 & evacuation & 26 & plan & 51 & rehabilitation & 76 & TEPCO \\
\hline 2 & Fukushima & 27 & staff & 52 & radiation & 77 & myself \\
\hline 3 & nuclear power plant & 28 & municipality & 53 & Tomioka & 78 & maintenance \\
\hline 4 & reconstruction & 29 & local area & 54 & high school & 79 & junior high school \\
\hline 5 & Hirono & 30 & prefecture & 55 & Tokyo Electric Power Co. & 80 & future \\
\hline 6 & accident & 31 & Naraha & 56 & construction & 81 & months \\
\hline 7 & resident & 32 & town & 57 & Kawauchi & 82 & open a school \\
\hline 8 & housing & 33 & school & 58 & city center & 83 & compensation \\
\hline 9 & earthquake disaster & 34 & education & 59 & place & 84 & situation \\
\hline 10 & Futaba & 35 & town people & 60 & Iwate & 85 & provision \\
\hline 11 & decontamination & 36 & disaster-affected & 61 & election & 86 & Tokyo \\
\hline 12 & Iwaki & 37 & lifting & 62 & preparation & 87 & agenda \\
\hline 13 & zone & 38 & damage & 63 & south & 88 & workers \\
\hline 14 & temporary & 39 & project & 64 & great earthquake & 89 & conference \\
\hline 15 & life & 40 & investigation & 65 & town hall & 90 & work \\
\hline 16 & facility & 41 & operation & 66 & family & 91 & consideration \\
\hline 17 & restart & 42 & job & 67 & district & 92 & set \\
\hline 18 & Tsunami & 43 & Okuma & 68 & student & 93 & revitalization \\
\hline 19 & repatriation & 44 & Miyagi & 69 & responding & 94 & rebuilding \\
\hline 20 & child & 45 & house & 70 & Japan & 95 & Koriyama \\
\hline 21 & locality & 46 & Namie & 71 & handling & 96 & effect \\
\hline 22 & support & 47 & schedule & 72 & company & 97 & radioactivity \\
\hline 23 & local governments & 48 & amount of radiation & 73 & remains & 98 & consistent \\
\hline 24 & mayor & 49 & disaster & 74 & government & 99 & reactor decommissioning \\
\hline 25 & Soma & 50 & disaster area & 75 & population & 100 & business \\
\hline
\end{tabular}

Note. These words are the top 100 nouns based on the relative frequency in total. Each noun has a frequency for each newspaper article. We applied correspondence analysis to the cross-tabulation table of these nouns. The italicized words show the names of places.

- I (in 2011): “election" (No. 61), "population" (No. 75), "Koriyama" (No. 95), "town hall” (No. 65), "house” (No. 45), “company” (No. 72), and "radioactivity” (No. 97). These nouns suggest the topics addressed most frequently in newspaper articles in 2011 related to "town situation after nuclear accident."

- II (in 2012): "city center" (No. 58), "plan" (No. 26), "restart" (No. 17), "district" (No.67) and "radiation" (No. 52). These nouns suggest the topics addressed most frequently in newspaper articles in 2012 related to "plan for restarting district in city center after radiation accident."

- III (in 2013): "repatriation" (No. 19), "town" (No. 32), "conference" (No. 89), "set" (No. 92), "decontamination" (No. 11), and "consideration" (No. 91). These nouns indicate the topics addressed most frequently in newspaper articles in 2013 related to "consideration of issues concerning the nuclear accident." 


\section{Macrothink

- IV (in 2014): “open a school” (No. 82), “education” (No. 34), “consistent” (No. 98), and "revitalization" (No.93). These nouns indicate the topics addressed most frequently in newspaper articles in 2014 related to "revitalization of school education."

- V (in 2015): "remains" (No. 73), "future" (No. 80), "investigation" (No. 40), "student" (No. 68), "operation" (No. 41), and "high school" (No. 54). These nouns indicate the topics addressed most frequently in newspaper articles in 2015 related to "investigation of remains" and, as in 2014, "new high school in Hirono."

\subsection{Session- and Newspaper-Based Analysis}

Table 5 shows the 100 nouns most frequently used in both the sessions and the newspaper articles as identified in the session-and-newspaper based analysis. Each noun has a frequency for each session and for each newspaper article. We applied correspondence analysis to the cross-tabulation table of these nouns. The result of the session-and-newspaper based analysis is shown in Figure 3. The contribution rates were $28.04 \%$ for dimension 1 and $16.64 \%$ for dimension 2.

In Figure 3, Roman numerals I through V (years of publication) were plotted close together, whereas letters A through F (sessions) were plotted far from each other. This indicates a huge difference among the contents of the discussions in each session, and little difference among the contents of newspaper articles in the five years.

In sessions $\mathrm{A}$ and $\mathrm{C}$, there were probably topics of discussion in common with those found in newspapers because both sessions were plotted close to the newspaper articles. There were also some common nouns among session $\mathrm{C}$ and the articles in groups III, IV, and V, such as "school" (No. 11), "high school" (No. 45), "student" (No. 68), "education" (No. 38), "advanced age" (No. 91), and "nursing care" (No. 83). Issues related to the topics of "school education" and "healthcare for the elderly" were probably reported in newspapers.

On the other hand, sessions D, E, and F were plotted far from the newspaper articles, indicating the presence of few nouns common to sessions $\mathrm{D}$ and $\mathrm{E}$ and the newspaper articles. The issues identified by residents in sessions D and E were "local retail shops in the disaster-affected area" and "workers at nuclear power plants." This result indicates a possibility that these two issues were not adequately reported in the newspaper articles. 
Table 5. Top 100 nouns of session- and newspaper-based analysis

\begin{tabular}{|c|c|c|c|c|c|c|c|}
\hline ID & Nouns & ID & Nouns & ID & Nouns & ID & Nouns \\
\hline 1 & evacuation & 26 & local governments & 51 & part & 76 & region \\
\hline 2 & Hirono & 27 & cooperation & 52 & town & 77 & mayor \\
\hline 3 & Fukushima & 28 & staff & 53 & information & 78 & opinion \\
\hline 4 & earthquake disaster & 29 & facility & 54 & relationship & 79 & disaster-affected \\
\hline 5 & reconstruction & 30 & Namie & 55 & together & 80 & handling \\
\hline 6 & nuclear power plant & 31 & lifting & 56 & town hall & 81 & reporter \\
\hline 7 & Futaba & 32 & support & 57 & industry & 82 & investigation \\
\hline 8 & resident & 33 & Tomioka & 58 & operation & 83 & nursing care \\
\hline 9 & life & 34 & zone & 59 & damage & 84 & Miyagi \\
\hline 10 & child & 35 & everybody & 60 & prefecture & 85 & Tokyo Electric Power Co. \\
\hline 11 & school & 36 & town people & 61 & teacher & 86 & population \\
\hline 12 & Iwaki & 37 & municipality & 62 & one & 87 & radioactivity \\
\hline 13 & situation & 38 & education & 63 & environment & 88 & Japan \\
\hline 14 & accident & 39 & Tsunami & 64 & healthcare & 89 & agenda \\
\hline 15 & saying & 40 & activity & 65 & compensation & 90 & disaster \\
\hline 16 & locality & 41 & previous & 66 & whole of country & 91 & advanced age \\
\hline 17 & myself & 42 & temporary & 67 & interview & 92 & amount of radiation \\
\hline 18 & local area & 43 & Soma & 68 & student & 93 & company \\
\hline 19 & job & 44 & restart & 69 & everyone & 94 & radiation \\
\hline 20 & decontamination & 45 & high school & 70 & actual state & 95 & public administration \\
\hline 21 & Naraha & 46 & place & 71 & responding & 96 & supermarket \\
\hline 22 & repatriation & 47 & project & 72 & Kawauchi & 97 & question \\
\hline 23 & housing & 48 & Tokyo & 73 & work & 98 & south \\
\hline 24 & workers & 49 & plan & 74 & disaster area & 99 & explanation \\
\hline 25 & Okuma & 50 & family & 75 & state & 100 & thoughts \\
\hline
\end{tabular}

Note. These words are the top 100 nouns based on the relative frequency in total. Each noun has a frequency for each session and for each newspaper article. We applied correspondence analysis to the cross-tabulation table of these nouns. The italicized words show the names of places. 


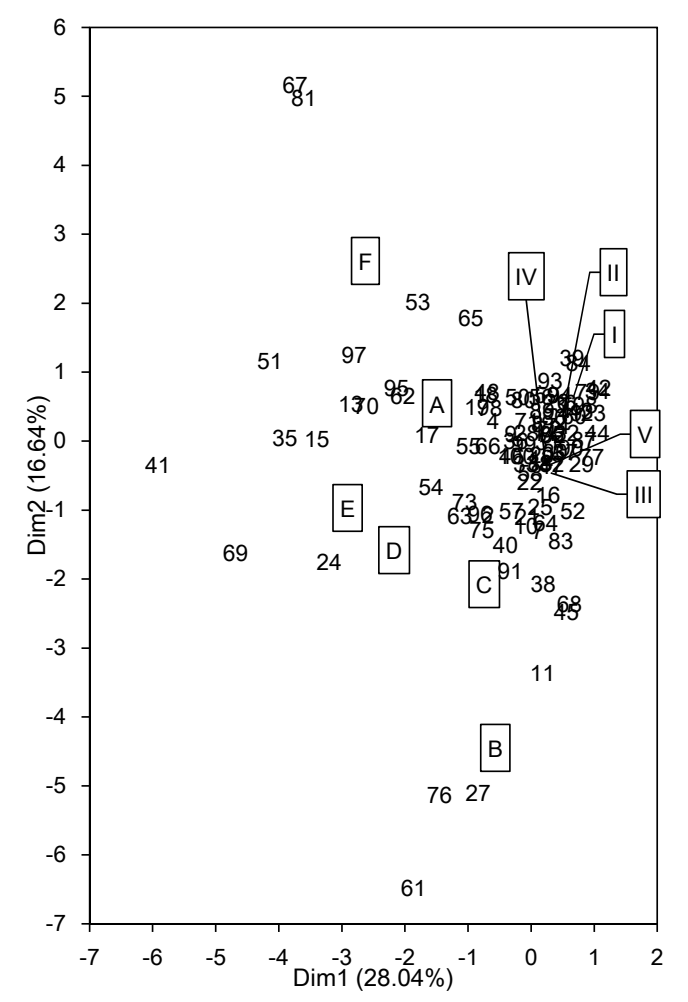

Figure 3. Result of correspondence analysis of each session and each newspaper article

Note. The numbers from 1 through 100 represent the nouns, letters A through $\mathrm{F}$ represent the sessions, and Roman numerals I through V represent the newspaper articles.

\section{Conclusion}

This study applied text mining to the text data from dialogue and newspaper reports about the reconstruction process areas affected by the Great East Japan Earthquake in 2011, identified the topics discussed by the residents, and tried to assess the information transparency in the media. Applying correspondence analysis to dialogue data identified the topics discussed by the participants in each dialogue session and showed the differences among topics discussed. Likewise, applying the analysis to the newspaper article data identified the topics reported by journalists related to the process of reconstruction after the earthquake. The final step of the analysis revealed the differences between the topics, particularly those discussed by the session participants and those topics reported by the journalists.

The position and distance of the plotted nouns based on the correspondence analysis revealed the differences in the information from the dialogues and the media reporting. It turned out that the newspaper articles did not adequately address some of the important topics discussed in the dialogue sessions. In this study, however, we used national newspapers to compare the topics reported by journalists with those discussed by the residents of disaster-affected areas. To examine the level of information transparency in more detail, comparing the articles that appeared in a nation-wide newspaper with those from local newspapers may give further insight. 


\section{Acknowledgments}

This study was funded by the Mitsui \& Co. Environmental Fund; JSPS KAKENHI Grant Number JP15H02864; and the Graduate School of Frontier Sciences, University of Tokyo. Support was also provided by the Reconstruction Agency of the Japanese Government through Hirono Town in the Fukushima Prefecture.

\section{References}

Asahi shimbun digital. (2016). KIKUZO II VISUAL. Retrieved from http://database.asahi.com/ (Dec 4, 2016).

Brains, L. C., \& Wattenberg, P. M. (1996). Campaign issue knowledge and salience: Comparing reception from TV commercials, TV news and newspapers. American Journal of Political Science, 40(1), 172-193. http://dx.doi.org/10.2307/2111699

Chosokabe, M., Sakakibara, H., Miyaji, T., \& Nishimura, T. (2012). Analysis of WS discussion in participatory planning process. Proceedings of the 2012 IEEE International Conference on Systems, Man and Cybernetics, 2441-2445. http://dx.doi.org/ 10.1109/ICSMC.2012.6378109

Chosokabe, M., Umeda, H., \& Sakakibara, H. (2016). The contribution of social context to participatory planning processes within a Japanese community. Group Decision and Negotiation, 25(5), 923-940. http://dx.doi.org/ 10.1007/s10726-015-9466-2

Clausen, S. E. (1998). Applied correspondence analysis (1st ed.). Thousand Oaks, CA: Sage Publications, Inc. (Chapter 1)

Greenacre, M., \& Blasius, J. (Eds.). (1994). Correspondence analysis in the social sciences (1st ed.). San Diego, CA: Academic Press.

Higuchi, K. (2001). KH Coder. [Online] Available: http://khc.sourceforge.net/ (Jan 4, 2017).

Hirono town. (2016). Thinking from disaster affected areas and Hirono. Retrieved from http://www.town.hirono.fukushima.jp/data/open/cnt/3/1566/1/HIrono-Forum-Report_A4.pdf (Jan 4, 2017).

Jeong, H., Hatori, T., \& Kobayashi, K. (2007). Discourse analysis of public debate: A corpus-based approach. Proceedings of the 2007 IEEE International Conference on Systems, Man and Cybernetics, 1782-1793. doi: 10.1109/ICSMC.2007.4413973

Jeong, H., Shiramatsu, S., Hatori, T., \& Kobayashi, K. (2008). Discourse analysis of public debates using corpus linguistic methodologies. Journal of Computers, 3(8), 58-68. http://dx.doi.org/10.4304/jcp.3.8.58-68

Mannarini, T., \& Roccato, M. (2011). Uses of the term NIMBY in the Italian press: 1992-2008. Environmental Politics, 20(6), 807-825. http://dx.doi.org/10.1080/09644016.2011.617167

Ministry of Education, Culture, Sports, Science and Technology (2011). Restoration and revival following the Great East Japan Earthquake - Creative recovery, starting with the development of human resources. http://www.mext.go.jp/b_menu/hakusho/html/hpab201101/detail/1330449.htm (Jan 4, 2017).

Prince, V. (1989). Social identification and public opinion: Effects of communicating group 


\section{Macrothink}

Journal of Asian Development

ISSN 2377-9594 2017, Vol. 3, No. 1

conflict. American Association for Public Opinion Research, 53(2), 197-224.

\section{Copyright Disclaimer}

Copyright for this article is retained by the author(s), with first publication rights granted to the journal.

This is an open-access article distributed under the terms and conditions of the Creative Commons Attribution license (http://creativecommons.org/licenses/by/3.0/). 